Sharif University of Technology
Scientia Iranica
SCIENTIA
I RAN I CA

Research Note

\title{
Towards resilient structures
}

\author{
A.R. Khaloo* and M.H. Mobini \\ Department of Civil Engineering, Sharif University of Technology, Tehran, Iran.
}

Received 17 May 2015; received in revised form 8 August 2015; accepted 21 November 2015

\section{KEYWORDS}

Disaster;

Resiliency;

Performance criteria;

Functionality;

Structure types.

\begin{abstract}
A disaster is an adverse event resulting from natural processes of the Earth or sometimes from terrorist attacks. Since the concept of disaster resilience has become prominent, research and practice for making the cities resilient play an important role in urban management. Cities are composed of a variety of structures and providing the structural resiliency can protect them. Resilient structures are composed of a number of ideal performance criteria, which based on analysis, experiment, and past experience, are capable to withstand the required level of stress and deformation. In addition, durability, fire resistance, and other capabilities, such as being environmentally friendly with no considerable reduction in functionality, are some of their other characteristics. In this paper, according to various design needs of structures, major influencing parameters are introduced in order to attain resiliency. Even though not all structures can be managed to be totally resilient, in other words to resist all types of action situations, the trend is to provide as many functions as possible. For example, not all structures can be designed to withstand wind, earthquake, and explosion. Generally, structures may be designed and built for a certain kind of actions. In the end, general considerations will be demonstrated to provide structures with specific criteria for resiliency.

(C) 2016 Sharif University of Technology. All rights reserved.
\end{abstract}

\section{Introduction}

Disaster risk reduction is an investment, not a cost. It increases business returns. Mayors, local government officials, and decision makers must frequently deal with the impact of small- and medium-scale disasters - and less frequently with large-scale events - that arise from natural or man-made hazards [1]. Recorded disaster events worldwide indicate a relatively constant number of seismic events, but point to an increase in the number of storms and floods. In many parts of the world, the risks associated with weather-related hazards are on the rise (the risk of economic losses is also on the rise, although fewer deaths have been recorded). The number and intensity of floods, droughts, landslides, and heat waves as well as the seismic events and

*. Corresponding author.

E-mail addresses: Khaloo@sharif.edu (A.R. Khaloo); mobini_mh@mehr.sharif.edu (M.H. Mobini) terrorist attacks can have a major impact on urban systems and resilience strategies.

\section{Resilience concepts}

Resilience is the capability of a system to:

- Maintain acceptable levels of functionality during and after disruptive events;

- Recover full functionality within a specified period of time [2].

Figure 1 illustrates the functionality of systems during and after disruptive events. This figure is adapted from McDaniels (2008) and Bruneau (2003). Two areas can be observed in this figure. The first one presents the situations prior to disaster and is related to the modification and considerations before the events occur and the second one demonstrates the situations after the disaster and is related to 


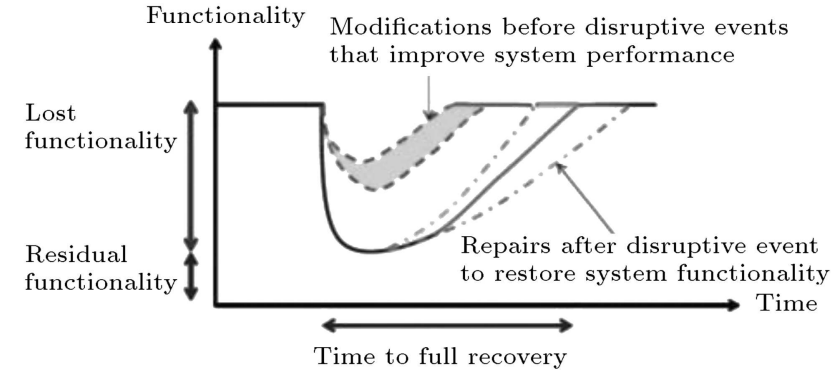

Figure 1. Functionality of systems during and after disruptive events.

the repairs after disruptive events. According to the important parameters of a structure, considerations before and after the disruptive events are taken into account. Some structures may lose their functionality after a specific disaster; this lost functionality may vary in different structures. The important keynotes are the modifications which improve system performance before disruptive events [3].

\section{Nature of damages by hazards}

As seen in Figure 2, a major terrorist attack, natural hazard, or accident causes four general types of damage: human casualties, environmental damage, psychological damage, and infrastructural damage. All of these also ultimately result in financial losses both directly and indirectly due to the socio-economic impact of the short-term or long-term loss of use of critical structure or infrastructure.

Human casualties can result directly from a hazard, and can be increased by structural collapse, breakout of fire, release of hazardous effluents, delays in the ability of people to evacuate, or delays in the arrival of the first responders to an incident. In the case of terrorism, controlling the number of human casualties are in the hands of the department of Homeland Security and state and local law enforcement [4]. It is worth mentioning that such a department was first established in United States after September 11 terrorist attacks. In the case of natural hazards, controlling the number of human casualties can be achieved by early warning for evacuation and disaster

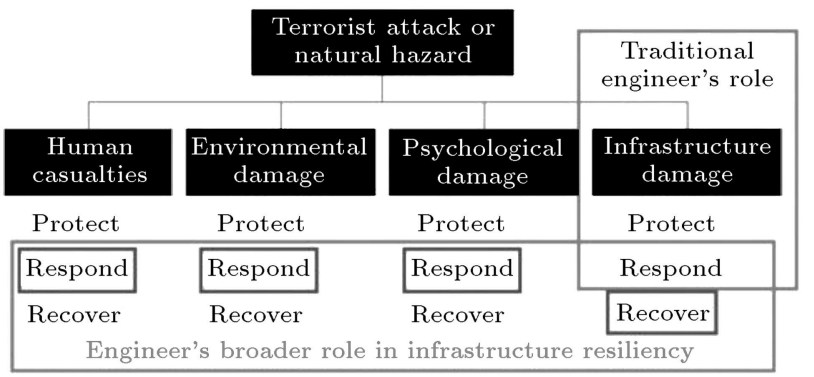

Figure 2. Nature of damages by hazards. planning. However, once a potential hazard occurs, it is the responsibility of the owner to provide protection, facilitate response, and plan for disaster recovery. This can be categorized as all-hazards or multi-hazard preparedness [5].

Traditionally, engineers have designed structures for loading defined by engineering practice and by the codes. This has gradually evolved. In the beginning, the practice was to limit stresses under live, dead, and wind load combinations to an allowable stress level that completely prevented any damage to structure [6]. This is shown in Figure 2 under infrastructure damage category as protect. As design practices evolved into load factor design and then into load resistance factor, design and seismic loading were taken into account; engineers began to take more account of probability of occurrence of each loading combination and designed to allow some residual damage and excessive deformation of structures provided that there was no instability or collapse; thus, evacuation could safely take place to limit human casualties. This is shown in Figure 2 under infrastructure damage category as respond.

\section{Extreme events - anticipating the unexpected}

Designing structures for resiliency shall address all four categories of hazards.

Once the hazard occurs, the correct reaction to the first three categories of damage would be to respond; and for the case of possible structural damages, the most efficient and cost-effective strategy is to design by consideration of recovery. Thus, measures should be taken, pre-event and post-event to make the recovery period of the critical structures and infrastructures as short as possible.

\subsection{Focusing of limited resources}

The primary objective of multi-hazard mitigation through resiliency is to focus resources $(\$$, people, equipment, and time) on:

- Mitigating the number of casualties;

- Shortening the recovery period (Resiliency).

\subsection{Implementation of mitigation to limit propagation of collapse}

Pre-disaster implementation of mitigation should be done by:

- Hardening, shielding, guarding, and/or insulating critical elements to prevent catastrophic failure;

- Providing redundancy to prevent local failure from progressing;

- Providing redundancy to maintain function of the system at a reduced level. 
Post-disaster implementation of mitigation should be done by:

- Making provisions to isolate or limit damage in the response mode;

- Preparing disaster recovery plans and procedures and arrange for resources to carry them out in an emergency recovery mode.

\subsection{Common terminology}

There are two common terminology for categorizing the critics and the society. The first one is the Hazard level that is used to describe the intense of disaster and the other one is the performance level which determine the resiliency of the structures and infrastructures:

- Hazard levels:

- Routine (serviceability);

- Expected (used in design and to evaluate resilience);

- Extreme (used in emergency response planning).

- Performance levels:

- Account for function of building or infrastructure system within the context of the community;

- Consider time to return to functionality.

\subsection{Performance goals for the "expected" disaster}

Performance goals for the expected disaster are shown in Table 1. Based on the importance and application, all of the structures and infrastructures are categorized in three phases of repair and reconstruction action. In this manner, almost all the city will come back to life in the period of three years.

Table 2 shows transparent performance measures for buildings in five categories. In this standard, all of the city buildings are designed for the specific and proper purposes and have their own repair priorities.

This new design methodology for civil engineering structures is called "Resilience-Based Design" (RBD), which can be considered as the next generation of Performance-Based Design (PBD). The goal of RBD is to make individual structures and communities as "Resilient" as possible through developing technologies and actions that allow each structure and/or community to regain its function as promptly as possible.

\section{The advantages of the resilient structure approach to multi-hazard events}

The resilient structure approach to multi-hazard events has different noteworthy advantages:

- Priority of life safety and emergency response issues through pre-event preparedness;

- Reducing the socio-economic impact of the loss of critical structures in an extreme event;

- Post-event, the precise location, and extent of damage to a system are known and resources can be effectively and quickly focused only on the location that requires repair;

- Overall investment of resources is the most efficient and cost-effective approach.

\section{Conclusions}

Due to the importance of resilient structure approach, the following conclusions are drawn:

- Designing resilient structural and infrastructural systems requires collaborative interdisciplinary efforts to formulate new approaches and metrics that jointly consider performance and post-event

Table 1. Performance goals for the "expected" disaster.

\begin{tabular}{lll}
\hline Phase & Time frame & \multicolumn{1}{c}{ Condition of the built environment } \\
\hline I & 1 to 7 days & Initial response and staging for reconstruction \\
II & 7 to 60 days & Ready workforce for housing restoration to meet primary social needs \\
III & 2 to 36 months & Long-term reconstruction \\
\hline
\end{tabular}

Table 2. Transparent performance measures for buildings.

\begin{tabular}{ll}
\hline Category & \multicolumn{1}{c}{ Performance standard } \\
\hline A & Safe and operational: Essential facilities such as hospitals and emergency operations centers \\
B & Safe and usable during repair: Shelter-in-place residential buildings needed for emergency operations \\
C & Safe and usable after repair: Current minimum design standard for new non-essential buildings \\
D & Safe but not repairable: Below current standards for new buildings, often used for voluntary retrofit \\
E & Partially unsafe or completely collapsed: Damage that will lead to casualties in the event of the \\
& expected disaster - the killer buildings \\
\hline
\end{tabular}


functionality goals that enhance disaster resilience. The engineering and functional aspects of critical buildings and infrastructural systems should be developed considering their lifetime with respect to impacts of disasters, repair, retrofitting interventions, and evolving urban dynamics. However, some considerations are necessary:

1. Spelling out the items that influence the required resiliency based on function of the structure;

2. Designing to provide optimal level of capacity for each item;

3. Not all the items could be completely overcome;

4. Resiliency is a relative subject.

- Resilient structural and infrastructural systems also require considering interdependencies with other systems, and ultimately how they affect the aftermath of emergencies and disasters;

- At this time, there are no explicit procedures that suggest how to quantify resilience for structures and infrastructures in the context of multiple hazards [7], how to compare structures and systems with one another in terms of their resilience, or how to determine whether individual retrofitting interventions in structures or facilities move them toward more resiliency;

- Different aspects of structural resiliency in a city, such as technical-socio-economic functionality of structures and infrastructures, probabilistic risk and resilience-based design principles for recommended practices and standards, environmental dependencies and interdependencies of individual and spatially distributed structures and infrastructures, optimal considerations in pre- and post-event retrofit and restoration, and resilience-based decision support systems for existing and new construction and dependent infrastructures, should be considered and taken into practice.

\section{References}

1. Mahriyara, M.Z. and Rho, J.H. "The compact city concept in creating resilient city and transportation system in Surabaya", Procedia - Social and Behavioral Sci., 135, pp. 41-49 (2014).

2. Wagnera, I. and Brei, P. "The role of ecohydrology in creating more resilient cities", Ecohydrology \& Hydrobiology, 13, pp. 113-134 (2013).
3. Dieleman, H. "Organizational learning for resilient cities, through realizing eco-cultural innovations", $J$. Clean. Prod., 50, pp. 171-180 (2013).

4. Desouzaa, K.C. and Flanery, T.H. "Designing, planning, and managing resilient cities: A conceptual framework cities", J. Cities, 35, pp. 89-99 (2013).

5. Anha, T.T., Giai Phongc, T.V. and Mulenga, M. "Community consultation for climate resilient housing: A comparative case study in Vietnam", Int. J. of Disast. Risk Reduc., 10, pp. 201-212 (2014).

6. Jabareen, Y. "Planning the resilient city: Concepts and strategies for coping with climate change and environmental risk cities", Cities, 31, pp. 220-229 (2013).

7. Satterthwaite, D. and Dodman, D. "Towards resilience and transformation", Env. and Urb. Brief-28 (2014).

\section{Biographies}

Alireza Khaloo received $\mathrm{PhD}$ from North Carolina State University. He has contributed and been involved in major projects such as Milad Tower and Masjed Soleiman Dam. Also, He had the main role in conducting different retrofitting projects such as refineries, petrochemical platforms, and sophisticated structures. Since 1988, he has been in the Civil Engineering Department at Sharif University of Technology, where he is currently a Distinguished Professor. Dr. Khaloo's research is related to behavior of reinforced and prestressed concrete structures, advanced concrete technology, earthquake engineering, and strengthening various types of structures.

Mohammad Hossein Mobini received the BSCE and MSCE degrees from Sharif University of Technology in 2008 and 2010, respectively. He was accepted as $\mathrm{PhD}$ candidate in 2011. He continued his education in Structural Engineering in the field of Advanced Concrete Composite under supervision of Prof. Khaloo. Moreover, he had some academic honors. He ranked 1st in nationwide Civil Engineering Olympiad in 2008 and ranked 2nd among more than 20,000 participants in the 2008 nationwide university exam for graduate studies. He achieved exceptional talented student title from the Office of Talent at Sharif University of Technology. 